\title{
A Rare Case of Stress-Induced Cardiomyopathy due to Intracranial Aneurysm
}

Yasuhiro Nakamura*, Rieko Ishimura, Takahide Kodama, Minoru Ono, and Sugao Ishiwata

Department of Cardiology, Toranomon Hospital, Japan

\begin{abstract}
Stress-induced cardiomyopathy (SICM) is characterized by transient systolic dysfunction of the apical and mid segments of the left ventricle without obstructive coronary artery disease. The precipitate causes are reported either an emotional or physically stressful event, which induces hyper-catecholamine secretion. It is extremely rare that SICM was induced by internal carotid artery (ICA) aneurysmal dilation. In this case report, we present an 86-year-old female patient with SICM induced by ICA aneurysm with panhypopituitarism, who on hormone replacement therapy had normalized asynergy.
\end{abstract}

Keywords: Stress-induced cardiomyopathy; Panhypopituitarism; Hypoglycemia; Intracranial aneurysm

\section{Introduction}

Stress-induced cardiomyopathy (SICM) is characterized by transient systolic dysfunction of the apical and/or mid segments of the left ventricle without obstructive coronary artery disease. A precipitate causes are reported such as an emotional or physically stressful event, which induces hyper-catecholamine secretion. It is rarely reported that SICM is induced by hypopituitarism and hypoglycemia.

\section{Case Report}

An 86-year-old female with coma was transferred to the emergency room. Prior to the transfer, the patient was found lying on the floor. The patient temporary regained consciousness and could communicate smoothly but gradually went back into a coma state (Glasgow Coma Scale-GCS: E2V3M4) during the travel to the hospital. Past history was remarkable such as left internal carotid artery (ICA) aneurysm (wait and see policy), complete AV block (treated with pacemaker placement), hypertension, hypertensive nephropathy and aortic valve stenosis. The patient's medication involved Cilostazol $100 \mathrm{mg}$ and Furosemide 30 mg. 12-leads electrocardiogram (ECG) performed in the emergency department showed pacemaker rhythm and ST depression in V2-4 leads (Figure 1). Laboratory data (Table 1), showed increased serum CK-MB level, electrolyte abnormality and decreased serum glucose concentration. Endocrine examination (Table 2), revealed decreased serum ACTH and thyroid hormonelevels, and increased serum prolactin level, which suggested panhypopituitarism. As a further investigation, we performed ultrasound cardiogram (UCG), which showed moderate

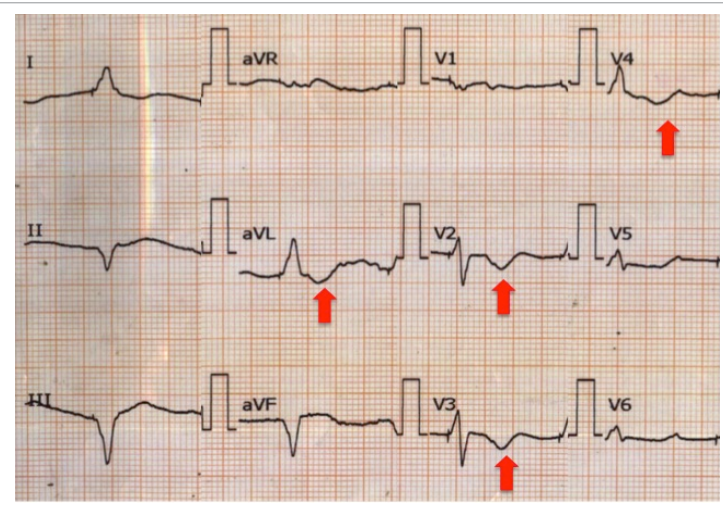

Figure 1: 12-leads electrocardiogram. It showed pacemaker rhythm and ST depression in V2-4leads. (Arrows).

\begin{tabular}{|c|c|}
\hline Parameter & Value \\
\hline \multicolumn{2}{|c|}{ CBC } \\
\hline WBC & $4700 / I A$ \\
\hline $\mathrm{Hb}$ & $11 \mathrm{~g} / \mathrm{dL}$ \\
\hline Plt & 134000/p.I \\
\hline \multicolumn{2}{|c|}{ Biochemistry } \\
\hline TP & $6.5 \mathrm{~g} / \mathrm{dL}$ \\
\hline Alb & $3 \mathrm{~g} / \mathrm{dL}$ \\
\hline BS & $1 \mathrm{mg} / \mathrm{dL}$ \\
\hline UN & $25 \mathrm{mg} / \mathrm{dL}$ \\
\hline $\mathrm{Crc}$ & $1 \mathrm{mg} / \mathrm{dL}$ \\
\hline LD & $336 \mathrm{IU} / \mathrm{L}$ \\
\hline CK & $354 \mathrm{IU} / \mathrm{L}$ \\
\hline CK-MB & $23 \mathrm{ng} / \mathrm{mL}$ \\
\hline $\mathrm{Na}$ & $134 \mathrm{mmol} / \mathrm{L}$ \\
\hline $\mathrm{K}$ & $3 \mathrm{mmol} / \mathrm{L}$ \\
\hline $\mathrm{Cl}$ & $99 \mathrm{mmol} / \mathrm{L}$ \\
\hline $\mathrm{Ca}$ & $8 \mathrm{mg} / \mathrm{dL}$ \\
\hline \multicolumn{2}{|c|}{ Immunology } \\
\hline CRP & $3.3 \mathrm{mg} / \mathrm{dL}$ \\
\hline
\end{tabular}

Table 1: Laboratory data on admission.

\begin{tabular}{|c|c|}
\hline Parameter & Value \\
\hline Cortisol & $7.2 \mathrm{p.g} / \mathrm{dL}$ \\
\hline Free T3 & $1.37 \mathrm{pg} / \mathrm{mL}$ \\
\hline ACTH & $<1.0 \mathrm{pg} / \mathrm{mL}$ \\
\hline Free T4 & $0.4 \mathrm{pg} / \mathrm{mL}$ \\
\hline GH & $0.8 \mathrm{ng} / \mathrm{mL}$ \\
\hline DHEA-S & $40 \mathrm{ng} / \mathrm{mL}$ \\
\hline Prolactin & $51.4 \mathrm{ng} / \mathrm{mL}$ \\
\hline LH & $<0.1 \mathrm{mIU} / \mathrm{mL}$ \\
\hline TSH & $1.883 \mathrm{I} . \mathrm{LIU} / \mathrm{mL}$ \\
\hline FSH & $0.9 \mathrm{mlU} / \mathrm{mL}$ \\
\hline E2 & $24 \mathrm{pg} / \mathrm{mL}$ \\
\hline
\end{tabular}

Table 2: Endocrine examination on admission.

*Corresponding authors: Yasuhiro Nakamura, Department of Cardiology, 2-2-2, Toranomon, Toranomon Hospital, Minatoku, Tokyo, Japan, E-mail: yasuhiro.n1112@gmail.com

Received May 14, 2017; Accepted May 22, 2017; Published May 25, 2017

Citation: Nakamura Y, Ishimura R, Kodama T, Ono M, Ishiwata S (2017)A Rare Case of Stress-Induced Cardiomyopathy due to Intracranial Aneurysm. J Cardiovasc Dis Diagn 5: 278. doi: 10.4172/2329-9517.1000278

Copyright: () 2017 Nakamura Y, et al. This is an open-access article distributed under the terms of the Creative Commons Attribution License, which permits unrestricted use, distribution, and reproduction in any medium, provided the original author and source are credited. 
impairment of left ventricle (LV) contraction (EF-ejection fraction: 48\%) (Figure 2). After administration of an intravenous bolus of $50 \%$ dextrose, coma improved rapidly (GCS: E4V5M6). We suspected this patient suffered SICM due to hypoglycemia, and then performed simultaneous dual-isotope myocardial SPECT with 123I-BMIPP and $201 \mathrm{Tl}$ (Figure 3). It revealed decreased accumulation of 123I-BMIPP in the apex and normal accumulation of 201Tl. The discrepancy of accumulation of 123I-BMIPP and 201Tl in the apex indicated that the impaired apical wall motion was not caused by ischemic heart disease, suggesting the diagnosis of SICM. As for examination of panhypopituitarism, head CT was performed, which revealed progressive dilation of ICA-aneurysm (Figure 4). We suspected direct compression and destruction of the surrounding normal pituitary leading to hyposecretion. Panhypopituitarism was treated by hormone replacement therapy (HRT) including intravenous administration of hydrocortisone and levothyroxine. HRT led to improve general condition and laboratory abnormalities. Also, 12-leads ECG and UCG on $16^{\text {th }}$ hospital day showed ST changes and LV contraction (EF 65\%) were normalized. At the time of discharge, the patient needed continuous HRT as oral hydrocortisone and levothyroxine administration.

\section{Discussion}

Our patient had coma due to hypoglycemia with focal wall motion abnormalities and abnormalities on ECG. Compression of the pituitary gland by dilated ICA-aneurysm resulted in panhypopituitarism. HRT resulted in normalization of LV contraction and clinical improvement.

Stress-induced cardiomyopathy (SICM) is characterized by transient systolic dysfunction of the apical and/or mid segments of the left ventricle without obstructive coronary artery disease. A precipitate causes are reported such as an emotional or physically stressful event,

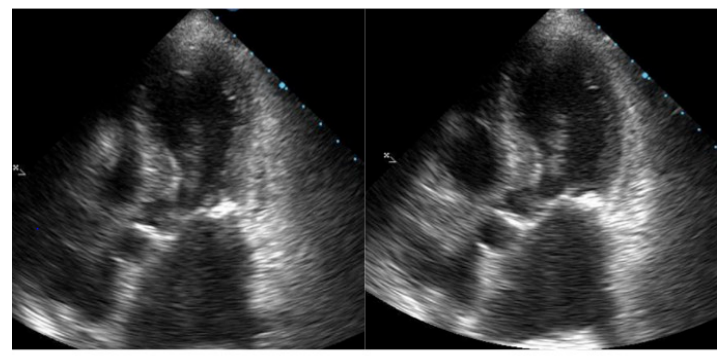

Systolic

Diastolic

Figure 2: Ultrasound cardiogram on admission. It showed $45 \%$ of ejection fraction and hypokinesis around apex.
TI scintigraphy

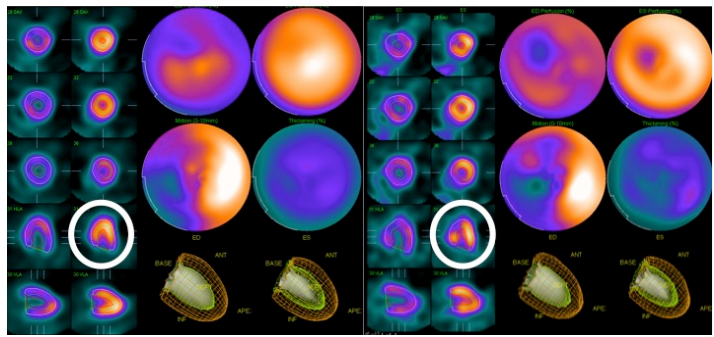

Figure 3: Simultaneous dual-isotope myocardial SPECT with 123I-BMIPP and $201 \mathrm{TI}$. It revealed the discrepancy of accumulation of 123I-BMIPP (Circle in right side image) and 201TI (Circle in left side image) in the apex indicated that the impaired apical wall motion was not caused by ischemic heart disease, suggesting the diagnosis of SICM.

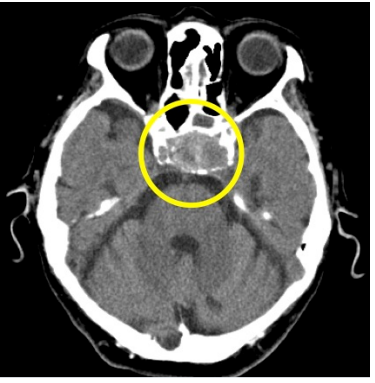

Figure 4: Head CT. It showed progressive dilation of aneurysm. (Circle).

which induces hyper-catecholamine secretion. The modified Mayo Clinic diagnostic criteria for SICM includes (1) transient hypokinesis, akinesis, or dyskinesis in the left ventricular mid segments with or without apical involvement; regional wall motion abnormalities that extend beyond a single epicardial vascular distribution; and frequently, but not always, a stressful trigger, (2) the absence of obstructive coronary disease or angiographic evidence of acute plaque rupture, (3) new ECG abnormalities or modest elevation in cardiac troponin, and (4) the absence of pheochromocytoma and myocarditis.

SICM, which was firstly reported in 1990, occurs predominantly in postmenopausal elderly women. Major symptoms are very similar to acute myocardial infarction such as chest pain, dyspnea, and ECG changes. Although the precise mechanism is not elucidated, proposed mechanism is that SICM is triggered by hyper catecholamine release which is response to an emotionally or physically stressful event like bereaving, heated argument, post-operative state, or severe sepsis [1]. Hyper-secretion of catecholamine produces coronary artery or microvascular spasms leading to necrosis of partial myocardium, direct toxic effect due to intracellular calcium concentrations increment or reactive oxygen species, and myocardial stunning induced by desensitization or down-regulation of receptor [2].

Acute hypoglycemia triggers activation of the sympathoadrenal system, leading to a release of epinephrine and other counter-regulatory hormones besides potent vasoactive peptides like endothelin. Consequently, there is increased cerebral, myocardial, and splanchnic blood flows with a decrease in blood supply to the skin and spleen [3]. In this case, hypoglycemia might have been associated with the onset of SICM. Furthermore, hypoglycemia can injure cardiac muscle by activating the coagulation system through an increase in factor VII, von Willebrand factor, C-reactive protein and inflammatory cytokines that are potentially leading to endothelial injury [4]. Also, subsidiary hemodynamic changes induced by sympathetic nervous system activation provide the substrate for possible myocardial ischemia [5].

The pathophysiology in this case was really complicated. Many several sequels are induced by dilated ICA aneurysm, which cause compression to the pituitary gland leading to panhypopituitarism. This train of events causes hypoglycemia and hyper catecholamine secretion, and finally results in SICM. The day when the patient was admitted to our hospital was a holiday. Therefore, we could not examine the serum catecholamine concentration at that time. Coronary angiogram was not performed because we did not strongly suspect myocardial infarction by echocardiogram that showed dyskinesis is not associated with coronary artery distribution, and renal dysfunction was reluctant us to use contrast by coronary angiogram. However, SICM was diagnosed by $\mathrm{Tl}+\mathrm{BMIPP}$ scintigraphy. Like other reports say SICM is cured without specific treatment, clinical course after admission was good with HRT. Although we considered the primary cause of this episode was dilated 
Citation: Nakamura Y, Ishimura R, Kodama T, Ono M, Ishiwata S (2017) A Rare Case of Stress-Induced Cardiomyopathy due to Intracranial Aneurysm. J Cardiovasc Dis Diagn 5: 278. doi: 10.4172/2329-9517.1000278

Page 3 of 3

ICA aneurysm, we have not treated this aneurysm because the surgical treatment of an aneurysm would not be beneficial to this age and we could favorably manage hypopituitarism by HRT.

Hypoglycemia rarely relates to SICM. In the previous case study of 88 SICM patients, only one case is considered that hypoglycemic episode associates to SICM [6]. To the best of our knowledge, this is the first case of SICM induced by ICA aneurysm. However, compression of the pituitary gland can be seen more often in the patients with the pituitary tumor as well. From this perspective, clinicians should be aware of this rare but curable cause of cardiogenic complication and recognize this can be severe physical stress again. Moreover, we state here a complicated pathophysiology for intracranial aneurysm-induced SICM and management from the initial critical presentation to the heart improvement.

\section{Conclusion}

We experienced SICM case with complicated pathophysiology. To the best of our knowledge, this is the first case report of SICM induced by ICA an aneurysm. Although the trigger of SICM is frequently reported as psychological stress, we need to consider SICM can occur under the severe physical stress.

\section{References}

1. Akashi YJ, Goldstein DS, Barbaro G, Ueyama T (2008) Takotsubo cardiomyopathy. Circulation 18: 2754-2762.

2. Kurisu s, Sato H, Kawagoe T, Ishihara M, Shimatani Y (2002) Tako-tsubolike left ventricular dysfunction with ST-segment elevation: A novel cardiac syndrome mimicking acute myocardial infarction. Am Heart J 143: 448-455.

3. Hekimian G, Kharcha F, Bréchot N, Schmidt M, Ghander C (2016) Extracorporeal membrane oxygenation for pheochromocytoma-induced cardiogenic shock. Ann Intensive Care 6: 117.

4. Wright RJ, Frier BM (2008) Vascular disease and diabetes: Is hypoglycaemia an aggravating factor?. Diabetes Metab Res Rev 24: 353-363.

5. Galloway PJ, Thomson GA, Fisher BM, Semple CG (2000) Insulininduced hypoglycemia induces a rise in C-reactive protein. Diabetes Care 23 861-862.

6. Tsuchihashi K, Ueshima K, Uchida T, Oh-mura N, Kimura K (2001) Transient left ventricular apical ballooning without coronary artery stenosis: A novel heart syndrome mimicking acute myocardial infarction. J Am Coll Cardiol 38: 118. 